\title{
Personalized prediction of mode of cardiac death in heart failure using supervised machine learning in the context of cardiac innervation imaging
}

\author{
Rudolf A. Werner, $M D,{ }^{a}$ Thorsten Derlin, $M D,{ }^{a}$ and Frank $M$. Bengel, $M D^{a}$ \\ a Department of Nuclear Medicine, Hannover Medical School, Hannover, Germany
}

Received May 11, 2020; accepted May 11, 2020

doi: $10.1007 / \mathrm{s} 12350-020-02215-z$

See related article, pp. 190-201

In recent years, the use of artificial intelligence (AI) has attracted interest for numerous medical imaging tasks. ${ }^{1}$ Striving to identify comparable or even identical patterns in large datasets, $\mathrm{AI}$ and its subdomain machine learning (ML) may hold promise to address the urgent need of analyzing complex interactions between multiple data points, ultimately allowing to identify high-risk individuals prone to major clinical events, to speed up clinical trials by selecting the most suitable candidates, or to provide therapeutic guidance by offering personalized treatment. ${ }^{2}$

In general, ML is based on the concept of probability. Based on previously fed data, ML makes assumptions with an increasing degree of certainty. Implementation of feedback loops allows for learning, i.e., after being told that the initially chosen decision was incorrect and will not lead to a favorable outcome, the procedure will be modified and the task will be reassessed by the ML algorithm until the desired expectations have been met. ${ }^{2,3}$

Funding This work was funded by the German Research Foundation (DFG), through the PRACTIS - Clinician Scientist Program of Hannover Medical School (ME 3696/3-1, RAW) the research group KFO311 (FMB) and REBIRTH cluster of excellence ("Förderung aus Mitteln des Niedersächsischen Vorab", RAW). No potential conflicts of interest relevant to this article exist.

Reprint requests: Rudolf A. Werner, MD, Department of Nuclear Medicine, Hannover Medical School, Hannover, Germany; werner.rudolf@mh-hannover.de

J Nucl Cardiol 2022;29:202-3.

$1071-3581 / \$ 34.00$

Copyright (c) 2020 The Author(s)
In a manner similar to myocardial perfusion imaging which had a pioneering role in nuclear medicine in the early $1970 \mathrm{~s},{ }^{4,5}$ nuclear cardiology is again at the forefront of innovation in molecular imaging by applying supervised ML for outcome prediction to different clinical scenarios. ${ }^{6,7}$ In the present issue of the Journal of Nuclear Cardiology, Nakajima et al. expanded the use of ML to the field of cardiac innervation imaging by incorporating the cardiac nerve radiotracer $\left[{ }^{123} \mathrm{I}\right]$ metaiodobenzylguanidine $\left(\left[{ }^{123} \mathrm{I}\right]-\mathrm{mIBG}\right)$ in an AI-based risk prediction model for segregating between low-risk vs high-risk patients potentially experiencing end-stage heart failure (HF) death or life-threatening arrhythmic events (ArE). Given the difficult management of these high-risk individuals, which includes cardioverter defibrillators and resynchronization therapy, reliable risk stratification is needed. To tackle this challenging task, the authors established an ML-based approach in the context of $\left[{ }^{123} \mathrm{I}\right]-\mathrm{mIBG}$ imaging, which could identify subjects at risk of fatal ArE and end-stage HF death. Interestingly, the ML-derived risk prediction model showed that risk for ArE was markedly elevated at the intermediate range of SPECT-derived heart-to-mediastinum ratio (HMR) in younger subjects with less severe HF. This finding can be explained by increased arrhythmogenicity of denervated but viable myocardium, in particular as the imbalance between preserved cardiac perfusion and impaired cardiac nerve integrity seems to be an important driver of serious arrhythmias. ${ }^{8}$ Moreover, in the present paper, Nakajima et al. could also verify the consistent correlation of HFrelated increase of death with decreased cardiac $\left[{ }^{123} \mathrm{I}\right]-$ mIBG uptake in the elder subjects with worse New York Heart Association (NYHA) functional class and higher frequency of comorbidities. These observations are in line with results of the ESC-Failure Pilot study, also reporting on increased prevalence of pump failure death 
in older patients with severe symptoms and worse NYHA status. ${ }^{9}$

Taken together, the present paper demonstrates that ML-based re-assessment of $\left[{ }^{123} \mathrm{I}\right]$-mIBG-derived HMR may be of relevance, as such an approach can not only predict one particular type of cardiac death mode in a restricted patient population, but is applicable to a broad range of various clinical settings, including congestive HF-related terminal endpoints in the elderly vs ArEdriven cause of death in younger subjects. These considerations may open avenues for a more sophisticated approach of applying ML to cardiac nerve PET radiotracers, as more detailed quantitative information derived by PET may hold promise to risk stratify between other high-risk individuals prone to major cardiovascular events. Established ${ }^{11} \mathrm{C}$ - and innovative ${ }^{18} \mathrm{~F}$-labeled PET radiotracers for cardiac nerve integrity are available ${ }^{10}$ and the improved spatiotemporal resolution of PET technology may allow for an in-depth assessment of sympathetic innervation of the myocardium, including quantification of regional heterogeneity such as the viable border zone after myocardial infarction. ${ }^{11}$ Compared to a global assessment of cardiac innervation as derived by SPECT-based HMR, the additionally gained quantitative data by PET could even further improve the herein presented risk estimations using ML-based classifiers. ${ }^{12}$ Moreover, PET enables for a non-invasive whole-body read-out and thus, information from other organs in the field of view could also be considered and fed into ML-based approaches for response prediction., ${ }^{4,13,14}$

\section{Disclosure}

Rudolf A. Werner, Thorsten Derlin, and Frank M. Bengel have no disclosures.

\section{Open Access}

This article is licensed under a Creative Commons Attribution 4.0 International License, which permits use, sharing, adaptation, distribution and reproduction in any medium or format, as long as you give appropriate credit to the original author(s) and the source, provide a link to the Creative Commons licence, and indicate if changes were made. The images or other third party material in this article are included in the article's Creative Commons licence, unless indicated otherwise in a credit line to the material. If material is not included in the article's Creative Commons licence and your intended use is not permitted by statutory regulation or exceeds the permitted use, you will need to obtain permission directly from the copyright holder. To view a copy of this licence, visit http://creativecommons.org/licenses/by/4.0/.

\section{References}

1. Giger ML. Machine learning in medical imaging. J Am Coll Radiol. 2018;15:512-20.

2. Rowe M. An introduction to machine learning for clinicians. Acad Med. 2019;94:1433-6.

3. Bastanlar Y, Ozuysal M. Introduction to machine learning. Methods Mol Biol. 2014;1107:105-28.

4. Werner RA, Thackeray JT, Diekmann J, Weiberg D, Bauersachs J, Bengel FM. The changing face of nuclear cardiology: Guiding cardiovascular care towards molecular medicine. J Nucl Med. 2020. https://doi.org/10.2967/jnumed.119.240440.

5. Zaret BL, Strauss HW, Martin ND, Wells HP Jr, Flamm MD Jr. Noninvasive regional myocardial perfusion with radioactive potassium: Study of patients at rest, with exercise and during angina pectoris. N Engl J Med. 1973;288:809-12.

6. Hu LH, Betancur J, Sharir T, Einstein AJ, Bokhari S, Fish MB, et al. Machine learning predicts per-vessel early coronary revascularization after fast myocardial perfusion SPECT: Results from multicentre REFINE SPECT registry. Eur Heart $\mathrm{J}$ Cardiovasc Imaging. 2020;21:549-59.

7. Arsanjani R, Dey D, Khachatryan T, Shalev A, Hayes SW, Fish $\mathrm{M}$, et al. Prediction of revascularization after myocardial perfusion SPECT by machine learning in a large population. J Nucl Cardiol. 2015;22:877-84.

8. Boogers MJ, Borleffs CJ, Henneman MM, van Bommel RJ, van Ramshorst J, Boersma E, et al. Cardiac sympathetic denervation assessed with 123-iodine metaiodobenzylguanidine imaging predicts ventricular arrhythmias in implantable cardioverterdefibrillator patients. J Am Coll Cardiol. 2010;55:2769-77.

9. Maggioni AP, Dahlstrom U, Filippatos G, Chioncel O, Crespo Leiro M, Drozdz J, et al. EURObservational Research Programme: Regional differences and 1-year follow-up results of the Heart Failure Pilot Survey (ESC-HF Pilot). Eur J Heart Fail. 2013;15:808-17.

10. Werner RA, Rischpler C, Onthank D, Lapa C, Robinson S, Samnick S, et al. Retention kinetics of the ${ }^{18}$ F-labeled sympathetic nerve PET tracer LMI1195: Comparison with 11C-hydroxyephedrine and ${ }^{123}$ I-MIBG. J Nucl Med. 2015;56:1429-33.

11. Werner RA, Chen X, Hirano M, Rowe SP, Lapa C, Javadi MS, et al. SPECT vs PET in cardiac innervation imaging: Clash of the titans. Clin Transl Imaging. 2018;6:293-303.

12. Bengel FM. Imaging targets of the sympathetic nervous system of the heart: Translational considerations. J Nucl Med. 2011;52:1167-70.

13. Thackeray JT, Hupe HC, Wang Y, Bankstahl JP, Berding G, Ross TL, et al. Myocardial inflammation predicts remodeling and neuroinflammation after myocardial infarction. J Am Coll Cardiol. 2018;71:263-75.

14. Derlin T, Thiele J, Weiberg D, Thackeray JT, Puschel K, Wester $\mathrm{HJ}$, et al. Evaluation of 68Ga-glutamate carboxypeptidase II ligand positron emission tomography for clinical molecular imaging of atherosclerotic plaque neovascularization. Arterioscler Thromb Vasc Biol. 2016;36:2213-9.

Publisher's Note Springer Nature remains neutral with regard to jurisdictional claims in published maps and institutional affiliations. 